\title{
0 espaço das desigualdades educativas no município de São Paulo
}

\author{
Graziela Serroni Perosa* , Frédéric Lebaron * * Cristiane Kerches da Silva Leite* * * \\ http://dx.doi.org/10.1590/0103-7307201507705
}

\section{Resumo}

Este artigo apresenta os resultados parciais de uma pesquisa sobre o estado atual das disparidades educacionais em São Paulo. A partir de uma Análise de Componentes Principais Standard (ACP), realizada com dados do Censo 2010/IBGE, identificou-se e comparou-se as características sociodemográficas da população do município e a distribuição de indicadores educacionais entre as regiões das subprefeituras da cidade. Isso permitiu examinar a relação entre posição social, condições de vida e usos socialmente diferenciados do sistema de ensino. Os resultados revelaram que, se um primeiro eixo opõe de maneira esperada os bairros ricos aos bairros pobres, um segundo revela uma divisão mais fina, no interior do espaço urbano, ligada à posse do diploma de ensino médio, que diferencia tanto as regiões de classes médias e altas, como as subprefeituras das periferias da cidade.

Palavras-chave: desigualdades educativas, indicadores educacionais, estrutura social, São Paulo

* Escola de Artes, Ciências e Humanidades e Programa de Pós-graduação em Estudos Culturais - Universidade de São Paulo (EACH/ USP), São Paulo, SP, Brasil. grazielaperosa@yahoo.com. br

** Laboratório Printemps, Université Versailles-SaintQuentin-en-Yvelines (UVSQCNRS) e Université ParisSaclay. Versailles, França. flebaron@yahoo.fr

*** Escola de Artes, Ciências e Humanidades e Programa de Pós-graduação em Gestão de Políticas Públicas, Universidade de São Paulo (EACH/USP), São Paulo, SP, Brasil. ckerches@uol.com.br 


\title{
The space of educational inequalities in the city of São Paulo
}

\begin{abstract}
This article presents the partial results of a research on the current state of educational disparities in São Paulo. Based on a Principal Component Analysis (PCA) of the IBGE 2010 Census data, the relationship between social position, life conditions, and the social uses of the educational system was analyzed. The results show that a first axis opposes, as expected, the rich and poor neighborhoods, and a second axis reveals a less evident opposition inside the regions. Based on high school credentials, this second opposition differentiates the neighborhoods in the middle and upper class regions as well as in the poorer regions of the city outskirts.
\end{abstract}

Keywords: : educational inequalities, educational indicators, social structure, São Paulo, Brazil 
São Paulo é uma cidade particularmente fértil para a análise das desigualdades educativas, pois reúne, desde o início do século XX, diversas categorias sociais: de banqueiros e grandes empresários a modestos operários e trabalhadores. ${ }^{1}$ Nessa cidade altamente desigual, a extrema pobreza e a extrema riqueza são pontos de um extenso contínuo constituído de posições intermediárias, que constituem uma forte demanda por instrução e educação. ${ }^{2}$ Este artigo apresenta resultados parciais de uma pesquisa sobre o estado das disparidades educacionais no município de São Paulo, tendo por base uma análise estatística, realizada com dados do Censo 2010/IBGE, na qual comparamos dados sociodemográficos da população e a distribuição de alguns indicadores educacionais visando obter uma síntese multidimensional atual do espaço social da cidade.

A noção de espaço social, proposta por Bourdieu (1979), nos incitou a apreender a cidade como um todo, passível de ser reconstruído com base em princípios de diferenciação pertinentes ao conjunto da população considerada (nível de renda, nível educacional e infraestrutura pública das subprefeituras). Os indivíduos são localizados nesse espaço pelas suas posições relativas em um “campo de forças" definido por relações objetivas, com as quais estão todos confrontados e que são irredutíveis às intenções dos agentes (Bourdieu, 2011). Assim, tanto os diferentes investimentos educativos, como as "patologias escolares"3, são pensados aqui como o resultado da relação possível com o sistema de ensino, derivada da posição das famílias na estrutura social. Os dados estatísticos foram tratados com o auxílio de técnicas de Análise Geométrica de Dados, em especial uma Análise de Componentes Principais, particularmente adaptada ao estudo de realidades multidimensionais e, por meio da qual, obtivemos uma representação do espaço social construída com base na distribuição das diferentes espécies de capitais (econômico, cultural, social e simbólico). ${ }^{4}$

1. 0 Índice de GINI de Renda varia de o a 1. Quanto mais próximo de 1, maior a desigualdade de renda. Nas últimas três décadas, o coeficiente de São Paulo piorou de 0,57 para 0,64 , em direção contrária à apontada pelo Banco Mundial, em estudo de 2012, que indicou redução do Índice de Gini na América Latina - de 0.530 no fim dos anos 1990 a 0.497 em 2010 -, em virtude do aumento na renda familiar e no tempo de escolarização, entre outros fatores. Fontes: http://tabnet. datasus.gov.br/cgi/ibge/censo/cnv/ginisp.def http:// raquelrolnik.wordpress.com/2011/01/25/0-que-dizemos-numeros-sobre-sao-paulo-em-comparacao-comoutras-cidades-do-mundo/;http://www.worldbank.org/ pt/news/feature/2013/01/25/Brazil-Argentina-Mexico-lead-fight-against-inequality; http://documents. worldbank.org/curated/en/2000/01/16867190/ declining-inequality-latin-america-2000s-casesargentina-brazil-mexico-declining-inequality-latin-america-2000s-cases-argentina-brazil-mexico. 2. Em 2010, a população paulistana entre o e 14 anos era de 2.360.901 pessoas; entre 15 e 19 anos, 850.354; entre 20 e 24 anos, 1.850 .068 . Fonte: http://infocidade.prefeitura.sp.gov.br/htmls/7_populacao_residente_por_grupos_de_idade_2010_595.html.

3. Inspirados em Durkheim, definimos "patologias escolares" como resultantes de dinâmicas estruturais do sistema de ensino, medidas aqui pelas taxas de evasão do Ensino Médio, de distorção série-idade e de reprovação. 4. Pierre Bourdieu utilizou este tipo de análise de dados estatísticos, como ferramenta para reconstruir empiricamente um determinado campo ou universo social. Ver, por exemplo: A distinção (1979), La noblesse d'Etat (1989) e Homo Academicus (1984). (Lebaron \& Le Roux, 2013). 
A pesquisa teve origem em uma interrogação relativa à chegada de escolas privadas na subprefeitura de Ermelino Matarazzo, distrito da periferia leste (Figura 1) onde, a partir de 1990, notamos o crescimento no número de escolas privadas. ${ }^{5} \mathrm{~A}$ análise estatística apresentada neste artigo teve como objetivo contribuir para a compreensão da posição desse distrito no interior do município de São Paulo ${ }^{6}$ e para a qualidade da ação pública em nível das subprefeituras. ${ }^{7}$ Os resultados permitem visualizar a relação entre posição social, condições de vida, usos socialmente diferenciados do sistema de ensino, em configurações urbanas extremamente desiguais. Possibilitam refletir sobre a escolarização dos filhos de famílias extremamente pobres que buscam sobreviver ao cotidiano, mas também sobre a emergência de estratégias educativas que exprimem uma visão de futuro, orientadas para o aumento da escolaridade.

\section{Sistemas de ensino e estrutura social}

A difusão dos sistemas de ensino foi acompanhada de uma clara segmentação interna (Ariès, 1981; Ringer, 2003), de hierarquização dos estabelecimentos de ensino (Bourdieu, 1989) e de estratégias de diferenciação do fluxo escolar (Muel-Dreyfus,

5. Em Ermelino Matarazzo, desenvolvemos outra etapa da pesquisa, ainda em andamento, com observações em escolas e domicílios e entrevistas com pais, professores e diretores. A pesquisa foi realizada graças à colaboração de Adriana Dantas, mestre em Estudos Culturais (EACH/ USP), e de Helena Marcon (bolsista de iniciação científica da FAPESP) e Isamara Lopes (bolsista PIBIC), ambas ex-alunas do curso de graduação em Gestão de Políticas Públicas (EACH/USP).

6. Agradecemos a Jean-Pierre Faguer (EHESS) pelo estímulo para identificar a posição relativa de Ermelino Matarazzo na cidade, por ocasião de sua visita a São Paulo como professor visitante (recursos da FAPESP), em 2012. 7. 0 estudo comparado de todas as subprefeituras teve início em setembro de 2012, período que antecedeu a eleição do atual prefeito de São Paulo (Fernando Haddad). 8. As meninas, por exemplo, chegaram ao sistema de ensino com cerca de 200 anos de atraso, como sugere o estudo de Philippe Ariès (1981). Apenas na segunda metade do século XX, os currículos de meninos e meninas foram unificados. Antes disso, expectativas sociais relativas ao papel feminino foram erigidas em disciplinas escolares (puericultura, prendas domésticas, preparação para 0 casamento, etc.), como bem argumentou Francine MuelDrefus (1998).
1975; Pinnel, 1995). De maneira bastante regular, houve, em diferentes contextos nacionais, uma transposição das desigualdades entre as classes sociais (e entre os sexos) para o interior dos sistemas de ensino. ${ }^{8}$ Analisando os casos da França e da Alemanha, entre 1865 e 1920, Fritz Ringer (2003) propõe que "a segmentação é a subdivisão em escolas e programas paralelos que se distinguem a uma só vez pelo currículo e pela origem social dos alunos" (p. 6). Tal segmentação pode se materializar entre as fileiras que conduzem à universidade e aquelas que conduzem à formação profissional. Nesse sentido, importa sublinhar que as distinções geradas no interior do sistema de ensino contribuem para legitimar a estrutura social, uma vez que as desigualdades sociais estão assentadas sobre as desigualdades educacionais. 
Neste estudo, nós partimos da realidade educacional brasileira atual, pós-expansão de matrículas dos anos de 1990 e 2000, para interrogar a produção das desigualdades educacionais. Ora, uma das principais formas de segmentação do sistema de ensino brasileiro é a diferenciação operada pelos estabelecimentos públicos e privados de educação. Mesmo que ambos os segmentos possam ser heterogêneos e desiguais entre si, os grupos sociais com maior renda e maior escolaridade tendem a manter seus filhos em escolas privadas, e os grupos com menor volume de recursos econômicos e escolares tendem a se concentrar nas estruturas públicas de ensino. ${ }^{9}$

Uma análise preliminar da distribuição da matrícula no município de São Paulo evidencia claramente a relação entre a posição na estrutura social das famílias e as subdivisões de ensino. A taxa média de matrículas no Ensino Fundamental II público, em 2010 , era de $79 \%$, contra $20,2 \%$ no setor privado. Tratar-se-ia de uma minoria numérica, pouco relevante para o exame das desigualdades educativas, se a distribuição da matrícula não fosse inteiramente desigual, com regiões nas quais a população possui baixa renda e menor escolaridade, com 99,9\% dos jovens na escola pública. No extremo oposto, nas poucas subprefeituras em que se concentram as famílias de maior renda e com ensino superior, $64 \%$ das matrículas estão na rede privada. No acesso ao Ensino Superior, a hierarquia escolar dos níveis precedentes se inverte. As universidades públicas são historicamente o local de formação das elites, ocupam uma posição dominante e seus diplomas conferem maior prestígio social. Nessas universidades, os estudantes de escolas privadas representam em média 60\% das matrículas, uma realidade, que dispositivos de políticas públicas recentes procuram alterar. ${ }^{10}$

Quando São Paulo se industrializou e a população cresceu de maneira acelerada, o déficit de vagas em educação tornou-se ainda mais forte, especialmente nas séries finais da escolarização. Por volta de 1940, quando a cidade chegava aos dois milhões de habitantes, a cidade possuía apenas três estabelecimentos de ensino secundário públicos (Spósito, 2002). Com o incentivo fiscal do Estado ${ }^{11}$, instalou-se um próspero mercado esco-

9. Em La Noblesse d'Etat, Bourdieu (1989) explora os significados da divisão entre o público e o privado na França, argumentando que ela é inseparável da recusa à escola laica, portanto, ao Estado laico e à filosofia republicana. A escola privada seria não apenas um ensino exclusivo, cujo limite é a figura do preceptor em domicílio do passado, mas também de "um ensino protegido, que busca transmitir as virtudes da moral conservadora, do trabalho, da família e da propriedade" (p. 401).

10. A partir de 2004, um "sistema de bônus" foi introduzido em exames de acesso a universidades estaduais paulistas (Unicamp em 2004, USP em 2006), visando a aumentar a participação de estudantes de escolas públicas. Esse sistema consiste na atribuição de uma pontuação suplementar nos exames de ingresso para estudantes que fizeram a escolarização básica e o Ensino Médio em escolas públicas. A Unifesp e a UFABC introduziram, recentemente, uma política de cotas raciais e sociais.

11. 0 incentivo se deu via incentivo fiscal, doação de terrenos e de valor simbólico agregado a estas instituições de ensino, na medida em que as elites e os homens públicos tendiam a matricular seus filhos no setor privado, católico e laico. (Perosa, 2004). 
lar que opera, há várias gerações, uma segregação de base financeira. ${ }^{12}$ Outras contingências históricas contribuíram para a formação dessa oferta escolar, composta por escolas públicas e privadas, laicas e religiosas, bastante desiguais entre si. Entre elas, a institucionalização da escola republicana na Europa e o consequente fechamento de escolas confessionais em países europeus, levando as ordens religiosas que aportaram ao Brasil, entre o século XIX e XX, a abrir internatos e colégios católi$\cos ^{13} \mathrm{O}$ fluxo imigratório do período impulsionou ainda a criação de escolas privadas por grupos de imigrantes em um período em que a dinâmica demográfica representava um importante desafio às políticas educacionais na cidade.

É verdade que os indicadores educacionais brasileiros melhoraram de maneira acelerada nas últimas décadas do século XX, com a expansão das matrículas em todos os níveis de ensino (Hasenbalg \& Valle, 2003). Entretanto, é preciso dizer que a expansão se deu por meio do acesso a estruturas escolares muito desiguais entre si. Diferenças de progressão no sistema de ensino, de acesso a um nível educacional e de escolhas de determinadas orientações são fortemente determinadas pelas características sociais e geográficas das famílias. Temos, ainda, crianças fora da escola e chances muito desiguais de acesso ao Ensino Superior entre os grupos sociais (Mont’Alvão Neto, 2014; Ribeiro, 2011). ${ }^{14} \mathrm{~A}$ preservação de fortes desigualdades no interior do sistema de ensino deu origem à expressão "democratização quantitativa”, na medida em que essa forma de acesso à escolaridade não permite reduzir as distâncias entre os grupos sociais (Garcia \& Poupeau, 2003). Neste contexto de generalização do acesso a estruturas escolares muito desiguais entre si e, de outro lado, de forte competição profissional no mundo do trabalho, as famílias tenderiam a desenvolver diversas estratégias que incluem o controle da fecundidade, a procura por determinadas escolas públicas, a escolha de uma escola

12. Almeida e Nogueira (2002).

13. A esse respeito, consultar Miceli (2009).

14. "Segundo o Censo do IBGE de 2010, o Brasil tem hoje 3,8 milhões de crianças e adolescentes, de 4 a 17 anos, fora da escola. Outros 8,8 milhões correm o risco de exclusão por causa do atraso escolar. A exclusão escolar no Brasil atinge, sobretudo, meninas e meninos negros, indígenas, pobres, com deficiência, os que vivem na zona rural, no Semiárido, na Amazônia, na periferia dos grandes centros urbanos." (Unicef, 2014). Infelizmente, em função da desatualização de alguns dados estatísticos sobre raça/cor para as subprefeituras de São Paulo, não pudemos ainda incorporar esta dimensão na pesquisa, mesmo reconhecendo sua pertinência. privada ou, até mesmo, a preferência por bairros que possuam boas opções de escolarização. Práticas que expressam estratégias familiares para manter ou alterar sua posição no espaço social. Para abordar este universo complexo e multifacetado, optamos por incluir uma grande variedade de indicadores sociais e educacionais e por fazer uma análise estatística multidimensional, capaz de oferecer uma síntese da relação entre o estado atual do sistema de ensino e da estrutura social no município de São Paulo. 


\section{Uma realidade muito desigual}

Atualmente, residem em São Paulo pouco mais de 11 milhões de habitantes 18 milhões, se considerarmos a região metropolitana -, em uma área de 1.530 km2 e com um dos dez maiores Produto Interno Bruto (PIB) do mundo. ${ }^{15}$ Para objetivar as distâncias neste espaço gigantesco, optamos por comparar a distribuição das características sociais da população e dos indicadores educacionais entre as subprefeituras, o que nos permitiu escapar, ao menos parcialmente, do uso exclusivo da média e da mediana, que não trazem informações sobre a distribuição dos recursos e dos fenômenos medidos entre os grupos sociais (Stiglitz, Sen, \& Fitoussi, 2012).

O universo considerado foram os 3.574.286 domicílios de São Paulo - distribuídos por 31 subprefeituras. ${ }^{16}$ As estatísticas utilizadas estão disponíveis em portais públicos e de organizações não governamentais, como o Infocidade, a Fundação SEADE e a Rede Nossa São Paulo. ${ }^{17}$ Utilizamos, principalmente, dados produzidos a partir do Censo 2010 (IBGE) relativos à renda dos domicílios, à escolaridade da população, à idade, à precariedade habitacional e ao desempenho no sistema de ensino. ${ }^{18}$ Longe de serem perfeitos, as estatísticas e o registro administrativo possuem diversos limites e lacunas, ligados em especial às operações de classificação. Isso não impede o seu uso, embora exija constante vigilância sobre o que os indicadores efetivamente medem e sobre a sua pertinência para o problema pesquisado. ${ }^{19} \mathrm{~A}$ escolha das variáveis inclui indicadores de características da população no que diz respeito ao volume e à estrutura do capital, e variáveis indicativas das propriedades sociais das subprefeituras.

15. A região metropolitana de São Paulo é a quinta maior do mundo, atrás de Tóquio, Nova York, Cidade do México e Bombaim. Se considerarmos só a cidade, é a sexta (Rolnik, 2011).

16. Desde 2001, São Paulo é dividida em subprefeituras, compostas por distritos, que, por sua vez, são formados por bairros e vilas. Cada subprefeitura possui entre 140.000 e 500.000 habitantes. Para saber quais distritos compõem as subprefeituras, veja: http://smdu.prefeitura. sp.gov.br/economia_urbana/mapas/mapaindice.pdf. Hoje a cidade possui 32 subprefeituras.

17. Com o Infocidade, a Secretaria Municipal de Desenvolvimento Urbano (SMDU) disponibiliza uma compilação de indicadores, cujas fontes são "as próprias secretarias da prefeitura, mas também instituições como o IBGE, a Fundação Seade e os Ministérios do Trabalho e Emprego, da Educação e da Saúde”. Ver: http://infocidade.prefeitura.sp.gov.br. 0 Movimento Nossa São Paulo é uma organização não governamental que surgiu em 2007. Ver: http://www.nossasaopaulo.org.br/.

18. Uma exceção é a taxa de fecundidade de 2002, disponibilizada pela Fundação SEADE.

19. Existem obstáculos ligados às mudanças históricas no uso das categorias, mas também derivados da possível dissimulação de fenômenos. Em especial, quando o registro estatístico é realizado por agentes diretamente implicados no fenômeno mensurado (Lebaron, 2006). 
Tabela1-

\section{Dezoito variáveis ativas}

\begin{tabular}{|c|c|c|c|c|}
\hline VARIÁVEIS ATIVAS & MÉDIA & $\begin{array}{l}\text { DESVIO- } \\
\text { PADRAि0 }\end{array}$ & MÍNIMO & MÁXIMO \\
\hline BIBLIOTECAS PÚBLICAS & 3,2 & 1,8 & 0,0 & 6,9 \\
\hline $\begin{array}{l}\text { DISTORÇÃO SÉRIE-IDADE } \\
\text { ENSINO FUNDAMENTAL II }\end{array}$ & 6,6 & 1,2 & 4,1 & 9,3 \\
\hline DOMICÍLIOS SEM ESGOTO & 9,1 & 11,4 & 0,1 & 65,4 \\
\hline $\begin{array}{l}\text { ENSINO FUNDAMENTAL II } \\
\text { INCOMPLET0 }\end{array}$ & 37,5 & 10,5 & 13,5 & 54,7 \\
\hline ENSINO MÉDIO COMPLETO & 26,5 & 2,7 & 18,9 & 31,7 \\
\hline $\begin{array}{l}\text { ENSINO SUPERIOR } \\
\text { COMPLETO }\end{array}$ & 16,3 & 14,1 & 3,0 & 54,5 \\
\hline HOMICÍDIOS & 6,9 & 3,4 & 1,3 & 15,2 \\
\hline LEITOS PÚBLICOS & 46,8 & 35,4 & 0,0 & 100,0 \\
\hline $\begin{array}{l}\text { MATRÍCULA ENSINO } \\
\text { FUNDAMENTAL I PUUBLICO }\end{array}$ & 79,7 & 16,7 & 36,2 & 99,9 \\
\hline $\begin{array}{l}\text { MATRÍCULA ENSINO } \\
\text { MÉDIO PÚBLICO }\end{array}$ & 82,9 & 15,8 & 44,4 & 100,0 \\
\hline $\begin{array}{l}\text { POPULAÇÃO COM } \\
\text { MAIS DE } 60 \text { ANOS }\end{array}$ & 11,8 & 4,0 & 6,0 & 19,7 \\
\hline $\begin{array}{l}\text { POPULAÇÃ0 ENTRE } \\
15 \text { E } 24 \text { ANOS }\end{array}$ & 16,2 & 2,0 & 11,5 & 19,0 \\
\hline $\begin{array}{l}\text { RENDA DE ATÉ } \\
1 \text { 1/2 SALÁRIO MÍNIM0 (SM) }\end{array}$ & 6,3 & 1,3 & 4,3 & 10,3 \\
\hline RENDA ENTRE 1-2 SM & 16,9 & 6,9 & 3,2 & 27,6 \\
\hline RENDA ENTRE 2-5 SM & 34,2 & 8,3 & 11,9 & 43,0 \\
\hline RENDA ENTRE 5-10 SM & 19,5 & 4,7 & 9,9 & 27,4 \\
\hline RENDA SUPERIOR A 20 SM & 5,9 & 8,1 & 0,0 & 30,6 \\
\hline TAXA DE FECUNDIDADE & 1,9 & 0,2 & 1,2 & 2,4 \\
\hline
\end{tabular}

Fonte: Elaboração dos autores

Pela Tabela 1, vemos como a média dos fenômenos considerados esconde realidades bastante díspares. A taxa média da população com Ensino Superior é de 16\%. Temos, entretanto, regiões em que apenas 3\% possuem este recurso e outras, nas quais 54\% possuem diploma superior. Com relação à renda, em média, são baixos os percentuais nos dois extremos: $6 \%$ recebem até $1 / 2$ salário mínimo e 5,9\% dos domicílios possuem renda superior a 20 salários mínimos. Contudo, há regiões em que até $55 \%$ dos domicílios recebem mais de 10 salários mínimos, enquanto em outras 
menos de $1 \%$ da população recebe tais rendimentos. Mesmo se considerarmos a heterogeneidade interna de cada subprefeitura, as desigualdades entre elas é enorme. As diferenças se fazem notar ainda na infraestrutura das subprefeituras. Temos regiões em que $100 \%$ dos domicílios contam com rede de esgoto, e no extremo oposto apenas 35\% (Parelheiros) possuem esse recurso. Globalmente, 34\% dos domicílios de São Paulo recebem entre 2 e 5 salários mínimos, e 19\% entre 5 e 10 salários mínimos. Assim como, 37\% da população não completou o Ensino Fundamental II, 26\% concluiu o Ensino Médio e 16\% tem Ensino Superior. Como argumentam Preteceille e Ribeiro (1999, p. 143), a maior parte dos estudos sobre as desigualdades sociais nas metrópoles contemporâneas enfatiza e ilustra a discussão com casos extremos, como se essas situações fossem representativas do conjunto da sociedade, obscurecendo as posições intermediárias. Uma das vantagens de trabalhar com a noção de espaço social e com técnicas de análise geométrica dos dados é a possibilidade de pensar a cidade como um todo, e os extremos como posições possíveis neste todo.

\section{Uma análise multidimensional}

Utilizamos uma Análise de Componentes Principais (ACP) standard, uma vez que os indicadores não estavam todos na mesma escala. ${ }^{20}$ Examinamos a estrutura das correlações estatísticas a partir do conjunto de 18 variáveis ativas (Tabela 1), cuja variância define o espaço das disparidades possíveis na cidade. A ACP reduz o número de dimensões importantes, criando um sistema baseado em eixos principais, em relação aos quais os indivíduos formam nuvens em função de sua dispersão (Lebaron, 2006). Nesse tipo de análise, podemos lançar mão das variáveis suplementares, projetadas sobre o espaço definido pelas variáveis ativas. Enquanto as variáveis ativas dizem respeito aos recursos sociais dos indivíduos, as variáveis suplementares referem-se às opiniões e às tomadas de posição que nuançam de maneira mais sutil as clivagens das estruturas sociais. A procura pelas escolas técnicas (Etec) ${ }^{\mathbf{2 1}}$, o abandono do Ensino Médio, a demanda por escolas privadas, a inscrição no vestibular da Fuvest são exemplos de variáveis suplementares, consideradas como tomadas de posição. ${ }^{22}$
20. A ACP foi realizada por meio do software SPAD 7.3. Agradecemos à Ana Maria Almeida (FE/Unicamp) que, graças aos recursos de reserva técnica da FAPESP, adquiriu a licença do software e nos concedeu uma licença de uso.

21. As Escolas Técnicas Estaduais - Etec - são instituições de ensino mantidas pelo governo do Estado de São Paulo e subordinadas ao Centro Estadual de Educação Tecnológica Paula Souza, que oferecem cursos técnicos e Ensino Médio. 0 Centro Paula Souza mantém ainda as Faculdades de Tecnologia - Fatec - , cujos cursos de graduação possuem duração de três anos (Ver: http://www. centropaulasouza.sp.gov.br/fatec/escolas/sao-paulo/). 22. Para uma discussão sobre as "tomadas de posição" em um determinado espaço social, consultar Bourdieu (2011) e Bourdieu (1979). 
A matrícula na escola privada poderia ter sido incluída no rol de variáveis ativas, como indicador de capital econômico. Entretanto, após vários testes, notou-se que essa variável aprofundava ainda mais o peso da distância entre as regiões ricas e pobres, o que dificultava a identificação de outras dimensões pertinentes. Por essa razão, optamos por considerá-la como indício de tomada de posição. Inserimos ainda, como suplementar, o voto no primeiro turno da eleição municipal de 2012. Se o Índice de Desenvolvimento da Educação Básica (Ideb) fica abaixo da média em toda a cida$d^{23}$, a média da reprovação escolar é baixa em toda a cidade (4,7\%) - como consequência de políticas de ciclos escolares e de "promoção automática” de âmbito nacional. Menos incidentes no conjunto da cidade, as taxas de reprovação quase dobram em condições de extrema pobreza e precariedade habitacional, passando para $7 \%$.

A Figura 1, a seguir, traz a disposição das 31 subprefeituras de São Paulo no espaço, que resulta da distribuição das 18 variáveis ativas (Tabela 1). Trata-se de uma representação das posições possíveis nesta estrutura social, baseada na distribuição do nível de renda dos domicílios e do nível educacional da população, mas também de outras dimensões, como a disponibilidade de serviços públicos, a idade da população ou a taxa de fecundidade. Nesse tipo de análise multidimensional, parte-se da observação da taxa de variância dos eixos que estruturam o espaço, e, em seguida, examina-se a estrutura de correlação entre as variáveis e a posição relativa das nuvens de indivíduos (subprefeituras) no espaço. ${ }^{24}$ Na Figura 1, o eixo 1 (horizontal) contribui com 60,43\% da variância do espaço e diz respeito à diferenciação sociodemográfica da população. Já o eixo 2 (vertical) contribui com 14,1\% da variância e distancia as subprefeituras com maior incidência de Ensino Médio e aquelas com

23. Desde os anos 1990, generalizou-se no Brasil a avaliação externa às instituições educacionais. Um dos indicadores de qualidade mais usados é o Índice de Desenvolvimento da Educação Básica (Ideb), determinado com dados do Sistema de Avaliação da Educação Básica (Saeb), combinando informações de desempenho e de rendimento escolar (Almeida, Dalben, \& Freitas, 2013). 0 Ideb é importante por colocar "o aprendizado e a regularidade na trajetória escolar dos alunos como elementos essenciais de um sistema educacional” (Soares \& Xavier, 2013, p. 904).

24. Aplicamos aqui o método de interpretação proposto por Brigitte Le Roux (2014).

25. Os eixos 3,4 e 5 não aparecem representados na Figura 1. menor infraestrutura pública. 0 eixo 3 é dado pela correlação entre desempenho escolar, pobreza extrema e violência, responsável por $7 \%$ da variância. Os eixos 4 e 5 respondem por 6,14\% e 4,18 \% da variância e não serão analisados aqui. ${ }^{25}$ 


\section{Figura 1- 0 espaço social das subprefeituras de São Paulo}

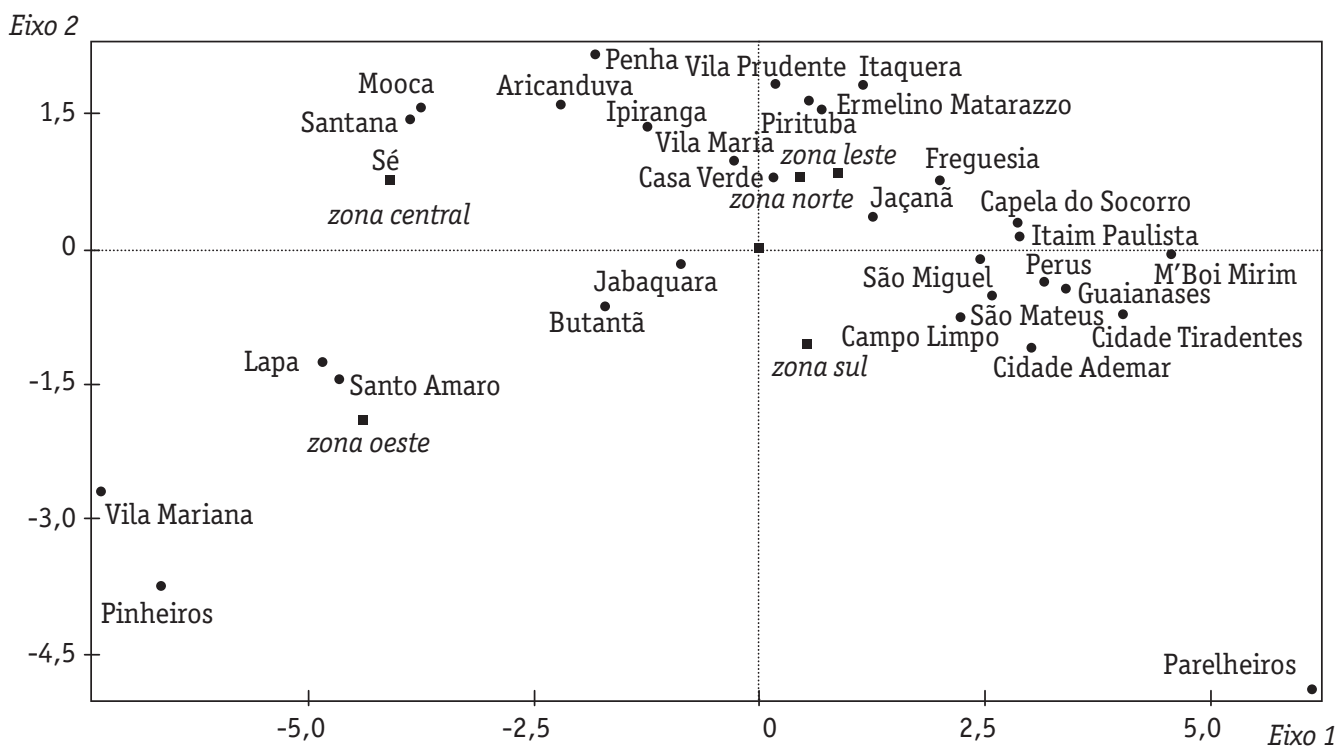

Fonte: Elaboração dos autores

\section{Figura 2- Círculo das correlações das variáveis ativas}

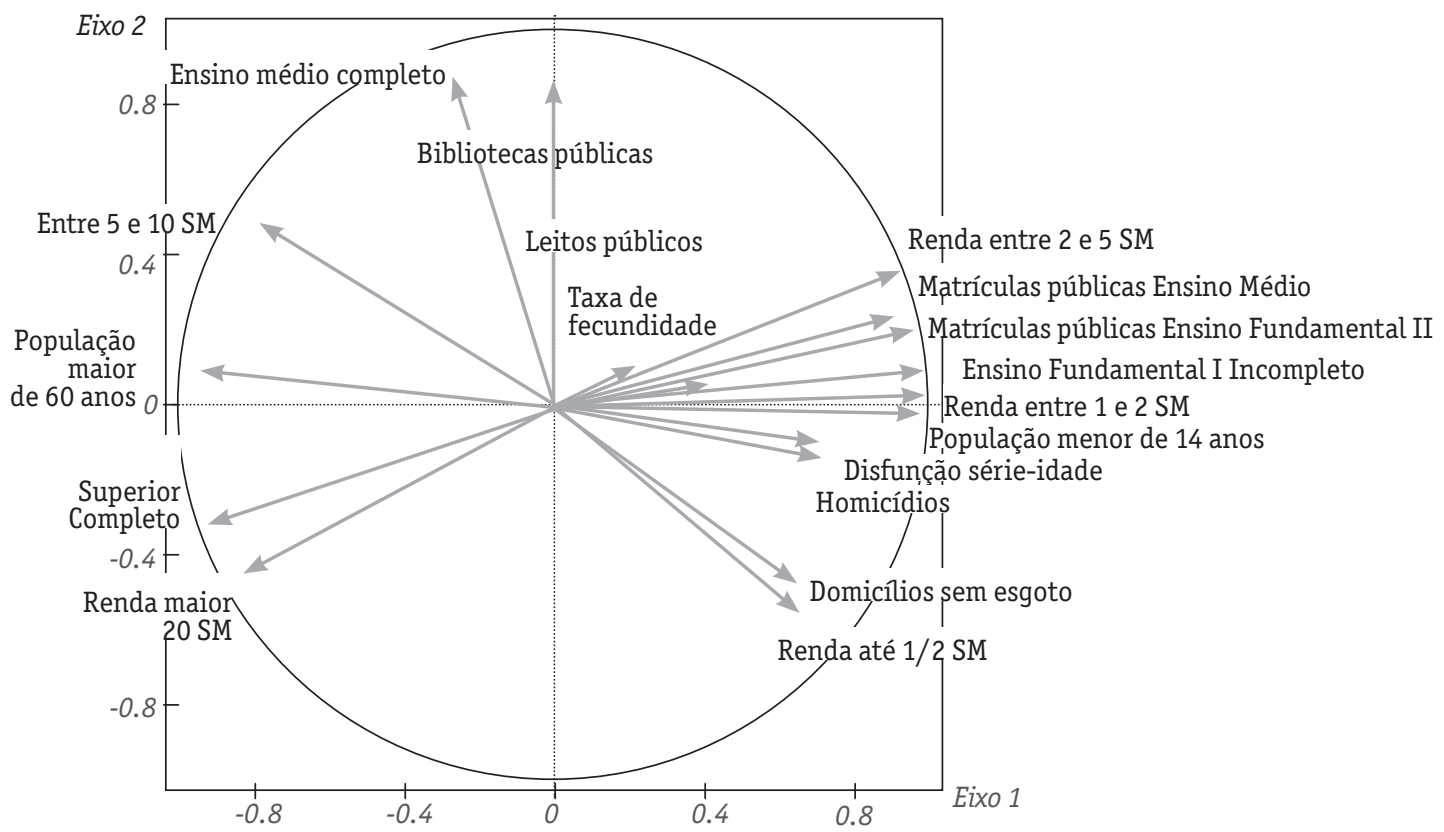

Fonte: Elaboração dos autores 
Vistas de maneira sobreposta, as figuras acima permitem apreender a disposição das subprefeituras no espaço social de São Paulo. A Figura 1 é definida pelas correlações estatísticas expressas na Figura 2. As flechas longas da Figura 2 indicam fenômenos mais concentrados em determinadas regiões, e as flechas curtas, dinâmicas mais bem distribuídas no espaço social. 0 eixo 1 distancia as poucas subprefeituras mais ricas e com maior percentual da população com Ensino Superior (Pinheiros e Vila Mariana), onde vive 5,7\% da população, de uma densa nuvem de subprefeituras (no quadrante inferior direito), em que vivem $24,2 \%$, em situação de pobreza, muitas vezes em condições indignas, com alto número de domicílios sem esgoto. Renda alta, maior escolaridade e longevidade estão fortemente correlacionadas no eixo 1. A renda entre 1 e 2 SM e entre 2 e 5 SM são positivamente correlacionadas e ambas negativamente correlacionadas aos extratos de renda superior a 20 SM e 5 a 10 SM, corroborando o que outros estudos já descreveram sobre os padrões de segregação social da cidade (Marques \& Torres, 2005; Villaça, 2001). Pinheiros e Parelheiros representam, assim, posições extremas não apenas pela maior concentração de domicílios de alta renda e alto nível educacional em Pinheiros, mas também pelas características da região de Parelheiros, que possui $65 \%$ dos domicílios sem rede de esgoto, situação atípica na cidade, o que a distancia de subprefeituras como Capela do Socorro e Perus, com 18\% e 13\% de domicílios nessa condição. 0 interesse maior do estudo são os eixos 2 e 3, que trazem clivagens menos evidentes da estrutura social.

O Eixo 2 (vertical) teve como principal variável a posse do diploma do Ensino Médio, trazendo à tona não só a diferença entre as subprefeituras das periferias, mas também as distinções entre as regiões dos grupos em posição intermediária, como as subprefeituras do tipo Mooca e Santana, e as do tipo Pinheiros e Vila Mariana. O Ensino Médio é negativamente correlacionado à pobreza extrema (renda até 1/2 SM e domicílios sem esgoto), mas também à renda superior a 20 SM. Assim, a incidência de diplomas de Ensino Médio emerge como um recurso protetor da precariedade absoluta e distingue as periferias entre si, bem como as regiões de classes médias e altas, em termos de volume de capital econômico e cultural. 0 Eixo 3, por sua vez, aponta uma correlação entre taxa de fecundidade, taxa de homicídio e a distorção série-idade. Uma correlação delicada, abordada por outros estudos ${ }^{26}$. Nunca é demais lembrar que correlação não quer dizer causalidade. Neste caso específico

26. Ver, em especial, os estudos etnográficos muito ricos realizados por Zaluar $(1985,1994)$. é preciso considerar que há a idade da população é uma variável subjacente que pode gerar este efeito 
de correlação, o que não implica em uma relação de causalidade e sim que nas regiões da cidade em que temos os maiores percentuais de jovens, temos também maiores taxas de homicídio, de distorção série-idade e também maior fecundidade.

\section{Reflexões sobre o espaço das desigualdades educativas}

A descrição dos dados, proporcionada pela ACP, permite retomar as hipóteses iniciais: i) a clivagem público-privado é uma clivagem social central do estado atual do sistema de ensino; ii) as configurações específicas das subprefeituras - ligadas tanto às características sociais da população, como à infraestrutura pública e educacional disponível - implicam em percursos escolares comuns a estudantes que vivem em condições semelhantes. Nas subprefeituras mais ricas (à esquerda do eixo vertical na Figura 1), nota-se a onipresença da matrícula privada, nos níveis do Ensino Fundamental e Médio, com taxas superiores a 60\% em muitas subprefeituras. No outro extremo da cidade (quadrantes à direita na Figura 1), 99\% das matrículas concentram-se na rede pública. Em distritos com posição relativamente intermediária, como Ermelino Matarazzo, nota-se um crescimento de escolas privadas, com $14 \%$ das matrículas em escolas privadas e $86 \%$ no ensino público.

Figura 3. Círculo de correlações e as variáveis suplementares

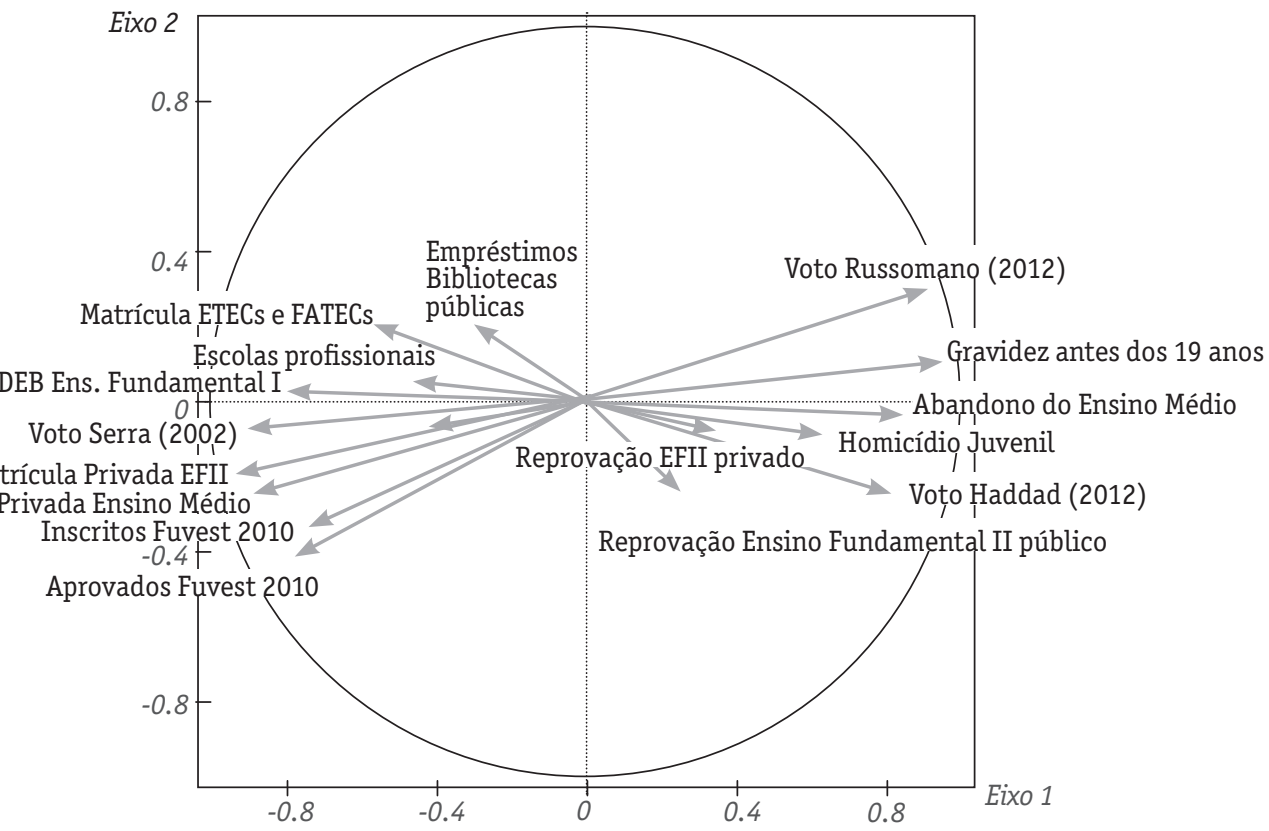

Fonte: Elaboração dos autores 
Nas subprefeituras mais ricas da Figura 1, concentram-se as escolas privadas que ocupam as primeiras posições nos rankings produzidos pela imprensa a partir dos resultados dos exames nacionais. Nessas regiões, uma única mensalidade escolar pode chegar a custar mais de mil dólares ao mês. Os usos do sistema de ensino neste extremo da cidade correspondem ao que descrevem os estudos sobre a escolarização dos grupos de elite, que incluem desde a escolha da escola à definição do tipo de preparação escolar e à inserção em redes de relações de amizade (Almeida \& Nogueira, 2002; Bonvin, 1979; Cookson \& Persell, 1985; Faguer, 1991; Saint-Martin, 1990). A lógica da aprovação nos vestibulares de acesso ao Ensino Superior impõe fortes investimentos econômicos para as famílias, exige o emprego de grande quantidade de energia e de tempo dos estudantes e, segundo alguns estudos, tende a resultar em uma relação com a cultura ao mesmo tempo dócil e segura, que predispõe ao exercício do poder (Wagner, 2012). A preparação para a competição escolar é feita por meio de um intenso trabalho pedagógico que exige a concentração dos estudantes em torno de preocupações escolares. ${ }^{27}$ Vemos também, na Figura 3, a presença mais forte de estruturas como as Escolas Técnicas (Etec), instaladas principalmente nos antigos distritos operários da cidade (Mooca) e nas regiões centrais (Sé). Trata-se de uma estrutura de Ensino Médio pública, cujo acesso é realizado mediante a aprovação em seletivos exames escolares e que possuem bom desempenho no Exame Nacional do Ensino Médio (Enem) ${ }^{28}$ Dentre as 50 escolas públicas com maior desempenho, 43 são escolas técnicas conhecidas como Etec. A procura pelas Etec e pelas escolas profissionais aparece correlacionada ao volume relativamente mais baixo de capital econômico e cultural (renda entre 5 e 10 SM e ao diploma de Ensino Médio), sendo menos incidente nos domicílios com renda superior a 20 salários mínimos. Assim, nas regiões socialmente intermediárias nota-se a presença de estratégias educativas visando ao aumento da escolaridade, como os indicadores de matrícula nas Etec, na Faculdade de Tecnologia do Estado de São Paulo - (Fatec) e de empréstimo nas bibliotecas públicas parecem expressar. 0 simples reconhecimento da presença desses

27. Uma ilustração desta realidade pode ser vista no filme de João Jardim, Pro dia nascer feliz (2006).

28. 0 Exame Nacional do Ensino Médio (Enem) foi criado em 1998, para avaliar a proficiência de alunos do Ensino Médio. 0 Enem é um instrumento desenvolvido para buscar garantir um currículo de base nacional (Santos, 2011), e para comparar o desempenho de estudantes em diferentes regiões do Brasil, ver Viggiano e Matos (2013). equipamentos públicos e a compreensão sobre o funcionamento do sistema de ensino dependem, na realidade, de certo volume de capital econômico e cultural (Bourdieu, 1979, p. 147). Uma hipótese possivel para explicar as estratégias educativas nos grupos intermediários é que a percepção agu- 
da das hierarquias do sistema de ensino - derivada da experiência de ter o Ensino Médio e não ter o Ensino Superior - contribui para o uso intenso de equipamentos públicos que oferecem maiores oportunidades educacionais. A distribuição socialmente diferenciada da taxa de matrículas na Fatec e das inscrições na Fuvest exprime um sistema duplo de acesso ao Ensino Superior, que conduz a carreiras desiguais entre si e socialmente hierarquizadas, pois os diplomas obtidos na Fatec não possuem o mesmo valor simbólico, quando comparados aos obtidos nas universidades públicas brasileiras, entre elas, a USP, cujo acesso se dá via o exame da Fuvest.

Nós já sabíamos que os trunfos (diplomas, capital cultural, etc.) e os handicaps escolares (abandono precoce, distorção série-idade, etc.) possuem forte correlação estatística com a posição social da família (Alves \& Soares, 2009; Bourdieu \& Passeron 2014; Hasenbalg \& Valle, 2003; Ribeiro, 2011). Nossos resultados confirmam esses estudos e lançam luz sobre dimensões menos exploradas na literatura, relativas ao papel do diploma de Ensino Médio na diferenciação da estrutura social brasileira, e as distinções, menos evidentes, no desempenho educacional dos jovens das periferias que não se restringem à renda e ao nível educacional dos pais. Durante quase todo o século XX, o Brasil teve altas taxas de reprovação desde as séries iniciais (Ribeiro, 1991), evasão geradas pelas sucessivas reprovações e “distorção série-idade”. ${ }^{29}$ Nossos resultados sugerem que o abandono escolar, a distorção série-idade e a reprovação não incidem da mesma forma em todas as periferias, ainda que elas possuam percentuais semelhantes da população com baixa escolaridade e baixa renda, as “patologias escolares” (reprovação, evasão e distorção série-idade) são muito mais acentuadas nas regiões em que as condições objetivas de vida são extremamente precárias (domicílios sem esgoto e com renda domiciliar de até 1/2 salário mínimo). Nessas condições, o investimento escolar torna-se muito mais difícil, raro e improvável.

Os resultados obtidos evidenciam como, ainda no século XXI, temos na cidade uma juventude tipicamente "burguesa” e a juventude abreviada dos grupos populares, frequentemente interrompida pelo abandono escolar, pela gravidez precoce e duplamente exposta à violência institucional: a violência policial descrita pelos estudos etnográficos de Alba Zaluar e Sérgio Adorno no Brasil; e a violência simbólica da instituição escolar, cujo veredicto escolar se assenta em representações negativas sobre os pobres e os moradores de favelas (Patto, 1990). Nas periferias menos precárias, a incidência de reprovação e dis-

29. Na década de 1980 , visando melhorar as estatísticas educacionais, foram introduzidos ciclos escolares sem reprovação, o que resultou na elevação (artificial) do desempenho do sistema de ensino brasileiro (Duran, Alves, \& Palma Filho, 2005; Viegas e Souza, 2012). 
torção série-idade é menor e cresce também o recurso às Etec e à escola privada. $A$ variável do voto na eleição municipal de 2012 ilustra mais uma vez as distinções entre as regiões da cidade. 0 voto em Fernando Haddad (Partido dos Trabalhadores) foi superior nas regiões mais precárias, entre a população extremamente pobre, que depende mais dos programas de transferência de renda, identificados com a gestão do Partido dos Trabalhadores (PT). Já o voto em Celso Russomano (Partido Republicano Brasileiro), candidato ligado à Igreja Evangélica, predominou entre os domicílios que ganham entre 2 a 5 SM.

\section{Considerações finais}

A primeira conclusão passível de ser extraída deste trabalho nos remete diretamente ao clássico debate sobre a reprodução da estrutura social e as desigualdades educativas, uma vez que a dimensão principal do espaço é dada pelo eixo 1, que responde por $60 \%$ da variância estatística. Não obstante, o interesse maior deste estudo reside menos na dualidade da estrutura social, já bastante analisada em outros trabalhos, e volta-se mais para a observação dos demais fatores, representados pelos eixos 2 e 3. 0 eixo 2 é definido pela dupla correlação negativa entre diploma de Ensino Médio e domicílios mais precários e também de renda intermediária (faixas entre 2 e 5 SM e entre 5 e 10 SM). Nesse espaço social, no qual em média, 37,5\% da população possui o Ensino Fundamental II incompleto (ver Tabela 1), podemos dizer, parafraseando Durkheim (2011), que o diploma do Ensino Médio age como um fator protetor da pobreza extrema. Esse nível educacional também distancia os indivíduos das faixas maiores de renda, resultando em uma posição social intermediária. 0 eixo 3 contribui para observarmos o que acontece com o desempenho escolar nas subprefeituras das periferias intermediárias e nas subprefeituras mais precárias.

Contra todo o tipo de essencialização e de psicologização dos determinantes do êxito escolar que rondam os valores da meritocracia e do senso comum, vemos como as condições materiais de existência - derivadas da renda, da escolaridade e das condições habitacionais - pesam brutalmente sobre os destinos educacionais. Nota-se, com maior acuidade, como o menor desempenho educacional não deriva apenas da baixa renda familiar e do menor nível educacional dos pais, mas da sobreposição destes fatores, a outras dimensões ligadas à infraestrutura pública dos domicílios. Por último, mas não menos importante, pode-se notar que o espaço das desigualdades educativas é também um espaço de lutas e de investimento no jogo escolar 
(não desistir, não abandonar, buscar as melhores alternativas da oferta escolar local, etc.) e, portanto, de illusio, de crença no valor dos títulos escolares, o que explica a emergência de diferentes estratégias educativas entre os grupos sociais em condições objetivas de aderir à lógica dos investimentos educativos. 


\section{Referências bibliográficas}

Adorno, S., Bordini, E. B. T., \& Lima, R. S. de. (1999). O adolescente e as mudanças na criminalidade urbana. São Paulo em Perspectiva [online], 13(4).

Agenda pela Infância 2015-2018. Desafios e Propostas eleições 2014. UNICEF, 2014. Recuperado em 22 de dezembro de 2014, de http://www.unicef.org/brazil/pt/ UNICEF_agenda2014.pdf.

Almeida, A. M. F., \& Nogueira, M. A. (2002). (Orgs.), A escolarização das elites: um panorama internacional da pesquisa (1a ed., Vol. 1). Petrópolis: Vozes. 222 p.

Almeida, L. C., Dalben, A., \& Freitas, L. C. (2013). O Ideb: limites e ilusões de uma política educacional. Educação \& Sociedade [online], 34(125), 1153-1174.

Alves, M. T. G., \& Soares, J. F. (2009, junho). Medidas de nível socioeconômico em pesquisas sociais: uma aplicação aos dados de uma pesquisa educacional. Opinião Pública,15(1), 1-30.

Ariès, P. (1981). A história social da criança e da família (D. Flaksman, trad., 2a ed.). Rio de Janeiro: Guanabara.

Bonvin, F. (1979, novembre). Une seconde famille: un collège d'enseignement privé. Actes de la recherche en sciences sociales, 30, 47-64.

Bourdieu, P. (1979). La distinction. Paris: Seuil, 1979.

Bourdieu, P. (1989). La Noblesse d'Etat. Paris: Seuil, 1989.

Bourdieu, P. (2011). Espaço social e gênese das classes. In P. Bourdieu, O poder simbólico. Rio de Janeiro: Bertrand Brasil.

Bourdieu, P. \& Passeron, J. (2014). Os herdeiros: os estudantes e a cultura (1a ed.). Florianópolis: Editora UFSC.

Cardia, N. (2005). Jovens, violência fatal, superposição de carências e mercado de trabalho. Núcleo de Estudos sobre Violência, USP. Recuperado em 22 de dezembro de 2014, de http://www.nevusp.org/downloads/downo74.pdf.

Cookson, P., \& Persell, C. (1985). Preparing for power. New York: Basic books.

Dantas, A. S. R. (2013). Por dentro da quebrada: a heterogeneidade social de Ermelino Matarazzo e da periferia. 23of. Dissertação de Mestrado, Escola de Artes, Ciências e Humanidades, Universidade de São Paulo, São Paulo.

Duran, M. C. G., Alves, M. L., \& Palma Filho, J.C. (2005). Vinte anos da política do ciclo básico na rede estadual paulista. Cadernos de Pesquisa [online], 35(124), 83-112.

Durkheim, É. (2011). O suicídio. São Paulo: Martins Fontes. 568p.

Faguer, J. P. (1991). Les effets d'une “éducation totale": un collège jésuite, 1960. Actes de la recherche en Sciences Sociales, 86-87,25-43. 
Garcia, S., \& Poupeau, F. (2003). La mesure de la "démocratisation" scolaire [Notes sur les usages sociologiques des indicateurs statistiques]. Actes de la recherche en sciences sociales, 149(149), 74-87.

Hasenbalg, C., \& Valle, N.(2003). Origens e destinos: desigualdades sociais ao longo da vida. Rio de Janeiro: Topbooks.

Lebaron, F. (2006). L'enquête quantitative en sciences sociales. Paris: Dunod.

Lebaron, F., \& Le Roux, B. (2013). Geometrie du champ. Actes de la Recherche em Sciences Sociales, 200, 106-109. Recuperado em 22 de dezembro de 2014, de http:// www.cairn.info/revue-actes-de-la-recherche-en-sciences-sociales-2013-5.htm

Le Roux, B. (2014). Analyse géométrique des données multidimensionnelles. Paris: Dunod.

Marques, E., \& Torres, H. (Orgs.) (2005), Segregação, pobreza e desigualdades so ciais (1a ed). Senac: São Paulo

Miceli, S. (2009). A elite eclesiástica brasileira: 1890 - 1930. São Paulo: Cia das Letras.

Mont’Alvão Neto, A. L.(2014, abril/junho). Tendências das desigualdades de acesso ao ensino superior no Brasil: 1982/2010. Revista Educação e Sociedade, 35(127) 417-441.

Muel-Drefus, F. (1975, janeiro). L'école obligatoire et l'invention de l'enfance anorma le. Actes de la recherche em sciences sociales, 1(1), 60-74.

Muel-Drefus, F. (1998). Vichy et l'éternel féminin : Contribution à une sociologie politi que de l'ordre des corps. Paris: Seuil.

Patto, M. H. S. (1990). A produção do fracasso escolar: histórias de submissão e rebeldia. São Paulo: T.A. Queiroz.

Perosa, G. S. (2004). Grupos familiares, investimentos educacionais e o mercado escolar em São Paulo. Pro-Posições, Campinas, 15(2), 61-75.

Pinell, P. (1995). L'invention de l'échelle métrique de l'intelligence. Actes de la recherche en sciences sociales, 108, 19-35.

Preteceille, E., \& Ribeiro, L. C. de Q. (1999). Tendências da segregação social em metrópoles globais e desiguais: Paris e Rio de Janeiro nos anos 80. Revista Brasileira de Ciências Sociais, 14(40), 143-162.

Ribeiro, C. A. C.(2011). Desigualdade de oportunidades e resultados educacionais no Brasil. DADOS, Revista de Ciências Sociais, Rio de Janeiro, 54(1), 41-87.

Ribeiro, S. C. (1991). A pedagogia da repetência. Estudos Avançados. 5(12), 07-21.

Ringer, F. (2003). La segmentation des systèmes d'enseignement [Les réformes de l'enseignement secondaire français et prussien, 1865-1920]. Actes de la recherche en sciences sociales, 149, 6-20. 
Rolnik, R. (2011). O que dizem os números sobre São Paulo em comparação com ou tras cidades do mundo? [on-line]. Blog da Raquel Rolnik. Recuperado em 5 de julho de 2014, de http://raquelrolnik.wordpress.com/2011/01/25/o-que-dizemos-numeros-sobre-sao-paulo-em-comparacao-com-outras-cidades-do-mundo/.

Saint-Martin, M. de. (1990). Une “bonne” éducation: les oiseaux à Sèvres. Ethnologie française, 20, 60-70.

Santos, J. M. C. T. (2011). Exame Nacional do Ensino Médio: entre a regulação da qualidade do Ensino Médio e o vestibular. Educar em Revista [online], 40, 195-205.

Soares, J. F., \& Xavier, F. P. (2013). Pressupostos educacionais e estatísticos do Ideb. Educação \& Sociedade [online], 34(124), 903-923.

Sposito, M. P. (2002). O povo vai à escola. A luta popular pela expansão do ensino público em São Paulo (4a ed.). São Paulo: Loyola.

Stiglitz, J., Sen, A., \& Fitoussi, J.P. (2012). Relatório da Comissão sobre a Mensuração de Desempenho Econômico e Progresso Social. Curitiba: SESI/PR. Recuperado em 22 de dezembro de 2014, de http://territorioobservatorio.files.wordpress. com/2013/o4/relatc3b3rio-da-comissc3a3o-sobre-a-mensurac3a7cзазо-dedesempenho-econc3b4mico-e-progresso-social.pdf.

Viégas, L. S., \& Souza, M. P. R. (2012). Promoção automática nos anos 1950: a experiência pioneira do Grupo Experimental da Lapa (São Paulo). Educação e Pesquisa 38(2), 499-514.

Viggiano, E., \& Mattos, C. (2013). O desempenho de estudantes no Enem 2010 em diferentes regiões brasileiras. Revista Brasileira de Estudos Pedagógicos [on-line]. 94(237), 417-438.

Villaça, F. (2001). Espaço intra-urbano no Brasil (2a ed). São Paulo: Studio Nobel: Fapesp: Lincoln Institute.

Wagner, A. C. (2012). La noblesse d’État et ses prolongements. In F. Lebaron, \& G. Mauger, Lectures de Bourdieu. Paris: Ellipses.

Zaluar, A. (1985). A máquina e a revolta: as organizações populares e o significado da pobreza. São Paulo: Brasiliense. 265p.

Zaluar, A. (1994). Cidadãos não vão ao paraíso. Campinas: Escuta.

Submetido à avaliação em 26 de setembro de 2014; aceito para publicação em 12 de fevereiro de 2015. 